\title{
Monitoramento e avaliação dos planos de educação: breves contribuições
}

\author{
Monitoring and evaluation of education plans: brief contributions \\ Monitorización y evaluación de los planes educativos: contribuciones breves
}

\section{LUIZ FERNANDES DOURADO GERALDO GROSSI JUNIOR ROBERVAL ANGELO FURTADO}

\begin{abstract}
Resumo: O presente artigo visa a situar a aprovação do Plano Nacional de Educação (PNE) por meio da Lei n. 13.005/2014 e dos planos decenais correspondentes elaborados pelos entes federados (estados, Distrito Federal e municípios), com ênfase nas questões atinentes ao monitoramento e avaliação dos planos. Parte-se do pressuposto analítico de que os processos de proposição e materialização de planos de educação são complexos e, portanto, não se efetivam de maneira linear, requerendo condições objetivas e políticas direcionadas ao efetivo cumprimento das metas e estratégias. Nesse contexto, no presente artigo, destaca-se que o planejamento, a proposição de políticas e a produção de indicadores se articulam ao processo de monitoramento e avaliação do plano entendido como epicentro das políticas educacionais.
\end{abstract}

Palavras-chave: Plano de Educação; monitoramento, avaliação, políticas educacionais.

\begin{abstract}
This article aims to situate the approval of the National Education Plan (PNE) through Act 13.005 / 2014 and the corresponding ten-year plans prepared by federal entities (states, Federal District and municipalities), emphasizing on issues related to monitoring and evaluation of the plans. This is on the assumption that the processes of proposition and materialization of education plans are complex and therefore do not become effective in a linear manner, requiring objective and political conditions aiming the effective implementation of goals and strategies. In this context, this paper points out that planning, proposing policies, and the production of indicators are linked to the process of monitoring and evaluation of the plan perceived as the epicenter of educational policies.
\end{abstract}

Keywords: Education Plan, monitoring, evaluation, educational policies.

Resumen: Este artículo tiene como objetivo situar la aprobación del Plan Nacional de Educación (PNE), a través de la Ley n. 13.005 / 2014 y la correspondiente a diez años de los planes elaborados por entidades federales (estados, Distrito Federal y municipios), con énfasis en las cuestiones relacionadas con la monitorización y evaluación de los planes. se parte de la suposición analítica de que los procesos de proposición y materialización de planes de educación son complejos y, por lo tanto, no se efectivan de manera lineal, lo que requiere condiciones objetivas y políticas direccionadas al efectivo cumplimiento de los 
objetivos y estrategias. En este contexto, en este artículo, se demuestra que la planificación, la propuesta de políticas y la elaboración de los indicadores se articulan con el proceso de monitorización y evaluación del plan visto como el epicentro de las políticas educativas.

Palabras clave: Plan de Educación, monitorización, evaluación, políticas educativas.

\section{INTRODUÇÃO}

A história recente da educação brasileira mostra avanços na discussão e implementação de diversas políticas que visam a assegurar direitos aos cidadãos e a ampliá-los, em consonância ao que preconiza a Constituição Federal e outros dispositivos legais. Entretanto, mesmo diante desses avanços, ainda se verificam fragilidades que marcam fortemente a consecução dessas políticas, principalmente quando analisadas sob a ótica do planejamento e da organização da educação, portanto, sua gestão e financiamento para além de curtos períodos de governo.

Importante ressaltar a análise feita por Dourado (2013), quando afirma que

O Estado brasileiro é marcado por desigualdades sociais e assimetrias entre os
entes federados e, por consequência, apresenta limites no horizonte de efetivação
dos direitos sociais e na capilaridade das políticas, com destaque para as políticas
educacionais. [...] A Constituição Federal (CF) de 1988 sinaliza novas diretrizes
para os direitos sociais no país, tendo por eixo um novo pacto federativo. Ela
estruturou a lógica política que sinaliza para a autonomia e o regime de colaboração,
a ser regulamentado entre os entes federados: União, estados, Distrito Federal e
municípios. [...] Tais questões não se dissociam de temas como reforma tributária,
novo pacto federativo e efetiva descentralização das políticas (sem perder de
vista a importância da coordenação nacional da União), que tenham por eixo a
regulamentação do regime de colaboração (p. 763 )

Assim, em um país com dimensões territoriais e características socioeconômicas e culturais tão diversificadas, como o Brasil, a busca pela efetivação de novos marcos no federalismo nacional, como espaço da cooperação, tornou-se necessária a implementação de espaços de interlocução nos quais os entes federativos, nas diversas instâncias, pudessem dialogar e propor o melhor caminho a ser trilhado. Nesse caso, as conferências de educação realizadas nos últimos anos se mostraram eficazes para a aproximação da sociedade na proposição, avaliação e defesa de planejamento orgânico para as políticas educacionais.

Nesse contexto, a Conferência Nacional de Educação (CONAE), que em duas edições (2010 e 2014) foi precedida pelas conferências municipais e 
intermunicipais, passando pelas conferências estaduais e chegando às conferências nacionais, discutiu amplamente várias temáticas, cuja incidência visava a impactar o processo de construção do Plano Nacional de Educação (PNE). Da primeira edição originaram-se temáticas, concepções e proposições que foram absorvidas, em parte, pelo projeto de lei do plano encaminhado pelo poder executivo ao Congresso Nacional. Na segunda edição, foi feita uma análise, meses após a sanção da Lei, ambas fortemente marcadas pela mobilização e participação social.

O Plano Nacional de Educação (2014-2024), Lei 13.005, de 25 de junho de 2014, não se constitui no primeiro documento dessa natureza em nosso País. No entanto, foi concebido sob a expectativa e o propósito de contrapor-se à lógica do plano anterior (Lei n. 10.1722001), contando com ampla participação social na sua formulação e se apresentando como caminho possível para a materialização de um plano de Estado direcionado, principalmente, para a melhoria da educação nacional e, desse modo, para o enfrentamento e superação das desigualdades educacionais latentes na sociedade.

A respeito do PNE anterior (Lei n. 10.172/2001), DOURADO (2011) afirma que,

Especificamente no tocante ao PNE, é fundamental destacar que sua aprovação, pelo Congresso Nacional, efetivou-se no Governo FHC por meio das estratégias políticas já delineadas e que sua efetivação ou não, se considerarmos a centralidade das políticas federais no campo educativo, obviamente que articuladas à ação de estados e municípios - responsáveis, no caso brasileiro, pela oferta majoritária da educação básica - deram-se no Governo Lula, a partir de 2003. [...] A tradição do Estado brasileiro, de políticas e gestão como resultante das ações e prioridades governamentais, stricto sensu, em detrimento de efetivas políticas de Estado, sofre injunções as mais diversas das estruturas políticas, econômicas, sociais e culturais após a aprovação do Plano e corroboram [...] a manutenção dessa complexa tessitura política na medida em que o atual PNE não foi considerado a base e a diretriz política central, no planejamento e na implementação das ações educacionais (p. 687).

O PNE 2014/2024 é composto por diretrizes, metas e estratégias que abrangem todos os níveis, etapas e modalidades da educação nacional. São vinte metas que podem ser agrupadas da seguinte forma: a) metas visando à garantia do direito à Educação Básica com qualidade, no que se refere ao acesso e à universalização dessa etapa da educação, incluindo a alfabetização e a ampliação da escolaridade; b) metas específicas para a redução das desigualdades e para a valorização da diversidade; c) metas para promoção da valorização dos profissionais da educação; d) metas relativas à avaliação e seus sistemas; e) metas referentes à Educação Superior; e) meta visando à regulamentação da gestão democrática e f) meta que trata especificamente do financiamento. 
Dentre outros dispositivos, o PNE determina uma série de encaminhamentos que reorganizarão a educação nacional para uma década como, por exemplo, a agenda instituinte do Sistema Nacional de Educação (SNE), o currículo para a Educação Básica, a política nacional de formação dos profissionais da educação, a valorização desses profissionais, a regulamentação da gestão democrática, a qualidade e o financiamento. São Diretrizes, metas e estratégias de amplo alcance, requerendo ações articuladas entre os entes federativos.

\section{A ELABORAÇÃO DOS PLANOS ESTADUAIS, DISTRITAL E MUNICIPAIS DE EDUCAÇÃO: MOVIMENTO HISTÓRICO NO PAÍS.}

A Lei 13.005/2014, que "Aprova o Plano Nacional de Educação e dá outras providências", estabeleceu em seu artigo $8^{\circ}$ que:

Os Estados, o Distrito Federal e os Municípios deverão elaborar seus correspondentes planos de educação, ou adequar os planos já aprovados em lei, em consonância com as diretrizes, metas e estratégias previstas neste PNE, no prazo de 1 (um) ano contado da publicação desta Lei (BRASIL, 2014).

A partir de então, iniciou-se um movimento envolvendo a ação articulada entre a União e os demais entes federativos visando à efetivação desses planos decenais. Para tanto, o Ministério da Educação (MEC), por meio da Secretaria de Articulação com os Sistemas de Ensino (SASE), cumprindo sua função supletiva, disponibilizou assessoramento aos estados, Distrito Federal e municípios com a instituição de uma rede de assistência técnica composta por avaliadores educacionais.

Para subsidiar a ação dos avaliadores educacionais e das comissões coordenadoras, foi disponibilizado no Portal Planejando a Próxima Década o conjunto de materiais, composto por documentos orientativos e fontes de pesquisas, para a construção dos indicadores das metas e estratégias que poderiam compor os planos subnacionais.

A rede de assistência técnica instituída para assessorar os entes federativos nesse processo foi composta em parceria com o Conselho Nacional de Secretários de Educação (CONSED) e com a União Nacional dos Dirigentes Municipais de Educação (UNDIME), com a indicação nos estados de profissionais com perfil técnico e conhecimento para a consecução da metodologia proposta pela SASE/ MEC.

Os documentos orientativos, que subsidiaram a ação da Rede, foram elaborados em parceria com renomados profissionais das universidades 
e instituições que atuam no contexto educacional em nosso País. Foram disponibilizados os seguintes materiais: a) Alinhando os Planos de Educação; b) Conhecendo as 20 Metas do Plano Nacional de Educação e c) O Plano Municipal de Educação: Caderno de Orientações.

Ao MEC coube, ainda, por meio de encontros e reuniões periódicas para estudos e discussões sobre a temática e suporte financeiro, a formação dos avaliadores, visando à atuação desses profissionais junto às equipes coordenadoras locais responsáveis pela elaboração ou adequação dos planos de educação.

Da metodologia sugerida constavam cinco passos elementares para o processo de elaboração ou adequação dos planos de educação, pensados para promover a mobilização e ampla participação social, de forma a legitimar os anseios e necessidades da sociedade para uma década, quais sejam: (1) definição e distribuição de responsabilidades; (2) elaboração do documento-base; (3) promoção de um amplo debate; (4) redação do projeto de lei e (5) acompanhamento e monitoramento da tramitação no legislativo.

Como parte da proposta de atuação da rede de assistência técnica, todos os entes federativos deveriam ser contatados pelos avaliadores educacionais e convidados a aderir ao assessoramento oferecido pelo MEC. Seguindo a autonomia que lhes é outorgada constitucionalmente, estados, Distrito Federal e municípios poderiam seguir a metodologia que melhor lhes conviesse para atendimento ao que preconiza o texto da Lei. É importante destacar que o apoio técnico da União, por meio da SASE/MEC, foi de grande valia para o processo de formulação ou adequação dos planos estaduais, Distrital e municipais, sobretudo se considerarmos as assimetrias entre os entes federados.

Ademais, com o objetivo de informar toda a sociedade sobre o trabalho realizado pelas equipes na elaboração ou adequação dos planos, o Portal "Planejando a Próxima Década" foi implementado de forma a apresentar a atualização periódica do processo, tendo como base a inserção de informação no Sistema Integrado de Monitoramento, Execução e Controle do Ministério da Educação (SIMEC), com a apresentação de mapas ilustrativos das unidades federadas e municípios com os status de desenvolvimento, permitindo o acompanhamento do estágio de implementação dos referidos planos.

Atualmente, a partir de consulta ao portal Planejando a Próxima Década, em 05/05/16, identificamos efetiva construção dos planos estaduais, distrital e municipais como é possível verificar nos indicadores expressos nos quadros a seguir: 
Quadro 1 - Situação dos Estados e do Distrito Federal

\begin{tabular}{|c|c|}
\hline Com documento-base elaborado & 1 \\
\hline Com projeto de lei enviado ao legislativo & 3 \\
\hline Com lei aprovada & 1 \\
\hline Com lei sancionada & 22 \\
\hline TOTAL & 27 \\
\hline
\end{tabular}

Fonte: Sistema Integrado de Monitoramento Execução e Controle do Ministério da Educação (Simec), em 05/05/2016.

Quadro 2 - Situação dos Municípios

\begin{tabular}{|c|c|}
\hline Com documento-base elaborado & 6 \\
\hline Com consulta pública realizada & 3 \\
\hline Com projeto de lei elaborado & 10 \\
\hline Com projeto de lei enviado ao legislativo & 38 \\
\hline Com lei aprovada & 5 \\
\hline Com lei sancionada & 5.506 \\
\hline TOTAL & 5.568 \\
\hline
\end{tabular}

Fonte: Sistema Integrado de Monitoramento Execução e Controle do Ministério da Educação (Simec), em 05/05/2016.

Esses indicadores sinalizam para avanços efetivos na construção dos planos por meio da constatação de que 22 Estados e 5.506 municípios tiveram seus planos sancionados. Nessa perspectiva, cabe destacar também que o Brasil viveu um grande movimento com as discussões e proposições dos temas relevantes para as políticas educacionais para longo prazo, sendo estabelecidas em leis, no âmbito de cada território, corroborando a manifestação das necessidades e especificidades locais e, consequentemente, a efetividade do PNE - que é o maior projeto de educação para a nação brasileira.

Importante é ressaltar, ainda, os limites que se apresentaram nessa caminhada, dada a complexa tessitura político-pedagógica que configura o cenário atual da educação nacional. Em alguns estados e municípios, os planos foram objeto de ampla mobilização e discussão, envolvendo diversos atores, institucionais ou não; em outros, o processo de participação ocorreu com menor intensidade.

\section{MONITORAMENTO E AVALIAÇÃO DOS PLANOS DE EDUCAÇÃO}

O Plano Nacional de Educação foi concebido sob a perspectiva da mobilização e da participação social, envolvendo profissionais que atuam 
diretamente em todos os níveis, etapas e modalidades da educação, assim como os cidadãos que contribuem para sua consecução. Garantir essa premissa é fundamental para a construção de planos de Estado.

Assim, ao analisarmos o extenso debate da tramitação do PNE no Congresso, podemos evidenciar a participação social como marca constante desse processo, em que pesem alguns limites setoriais, com disputas e posicionamentos sobre o texto das metas e estratégias que complementaram a fase de discussões e proposições iniciadas nas conferências que precederam a CONAE/2010, como assevera o fragmento abaixo retirado do Documento Final dessa Conferência:

O fato, portanto, de a Conae ter sido precedida por conferências estaduais, municipais e intermunicipais, com ampla mobilização e participação da sociedade, reveste-se da maior importância com a expressão do processo democrático. Esse envolvimento dos/das profissionais da educação e dos diferentes segmentos e setores da sociedade, ligados à educação, traduz a capacidade de mobilização, participação, criatividade e visão crítica dos movimentos sociais organizados, e de todos e todas profissionais da educação, ao assumirem a educação de qualidade como direito social (BRASIL, 2010, p.12).

Com a aprovação do PNE pelo Congresso Nacional e, consequentemente, com a sanção pela Presidente da República, torna-se imperiosa uma tarefa extremamente importante e necessária, qual seja o monitoramento contínuo e as avaliações periódicas das metas, estratégias e demais dispositivos constantes desse documento.

A Lei n. 13.005/2014 determina os responsáveis pelo processo em pauta, como podemos observar a seguir:

Art. $5^{\circ}$ A execução do PNE e o cumprimento de suas metas serão objeto de monitoramento contínuo e de avaliações periódicas, realizados pelas seguintes instâncias: [...] I - Ministério da Educação - MEC; [...] II - Comissão de Educação da Câmara dos Deputados e Comissão de Educação, Cultura e Esporte do Senado Federal; [...] III - Conselho Nacional de Educação - CNE; [...] IV - Fórum Nacional de Educação (BRASIL, 2014).

Sob tal enfoque, devemos atentar-nos para a relevância dessa ação, uma vez que sua organicidade dará movimento e dinamismo às diretrizes, metas e estratégias pensadas, discutidas e postas na forma de lei para viabilizar avanços para a educação nacional. Mais que isso, são fundamentais o acompanhamento, o monitoramento e a avaliação pelas autoridades competentes previstas no PNE e, ainda, a participação da sociedade no acompanhamento e no monitoramento, visando à efetivação do plano. 
Vale, ainda, refletir acerca das ações a serem implementadas a partir da demanda expressa no Artigo $5^{\circ}$ do PNE às instâncias incumbidas, bem como acerca do grande desafio imposto à sociedade na mobilização em torno da participação no cumprimento das metas e estratégias estabelecidas.

A partir dessa concepção, torna-se evidente a implementação de medidas capazes de conjugar os esforços de todos os envolvidos - gestores públicos, órgãos reguladores e de controle e sociedade - a fim de montar uma engrenagem eficiente na constatação dos rumos da política educacional edificada na forma da lei do PNE.

Em 2015, o Instituto Nacional de Estudos e Pesquisas Educacionais Anísio Teixeira (Inep) lançou o documento Plano Nacional de Educação - Linha de Base, em versão preliminar, constituído de análises descritivas das séries históricas dos indicadores que compõem o Plano, apresentados em diversos recortes (sexo, idade, renda, entre outros), disponíveis na data de sanção do PNE, em cumprimento ao seguinte dispositivo constante do Artigo 5º da Lei 13.005/2014:

\2o A cada 2 (dois) anos, ao longo do período de vigência deste PNE, o Instituto Nacional de Estudos e Pesquisas Educacionais Anísio Teixeira - INEP publicará estudos para aferir a evolução no cumprimento das metas estabelecidas no Anexo desta Lei, com informações organizadas por ente federado e consolidadas em âmbito nacional, tendo como referência os estudos e as pesquisas de que trata o art. 4o, sem prejuízo de outras fontes e informações relevantes (BRASIL, 2014).

Trata-se de um documento com informações para subsidiar os entes federativos na tarefa de monitorar e avaliar seus planos de educação. Esse material, além de atender ao dispositivo do PNE, é fundamental para subsidiar o acompanhamento, o monitoramento e a avaliação do cumprimento das metas e estratégias.

Às instâncias responsáveis por monitorar e avaliar o PNE fica o desafio de articular dados e informações e promover amplo debate em torno do cumprimento (ou não) do que foi previsto, o que pressupõe intensa mobilização social e articulação. No caso de descumprimento de metas e estratégias, compete a essas instâncias a proposição de repactuação de metas e estratégias para o período. Nesse viés, a participação da sociedade marca o controle das ações decorrentes do próprio Plano, num movimento em prol da melhoria contínua da qualidade da educação para todos.

Dessa forma, entende-se que monitorar e avaliar tornam-se partes constantes de um único processo, ou seja, etapas distintas e complementares que não se realizam isoladamente. Por essa ótica, a avaliação compreende o monitoramento como parte constitutiva e constituinte. 
Como decorrência do PNE, os planos de educação dos Estados, do Distrito Federal e dos Municípios também devem ser monitorados e avaliados periodicamente, com a verificação do cumprimento dos dispositivos legais e da implementação das políticas educacionais no âmbito de cada território, contribuindo, assim, para a efetividade do PNE, que só logrará êxito se todos os planos subnacionais cumprirem com os objetivos propostos.

Nesse sentido, os entes federativos devem ter clareza de que o monitoramento e a avaliação dos planos de educação tornam-se elementos imprescindíveis à tomada de decisões dos gestores públicos, visando a garantir a relação eficiência, eficácia e efetividade do que foi planejado, os possíveis ajustes no percurso, a participação da sociedade e a transparência necessária.

Ademais, os planos de educação devem ser avaliados periodicamente, com base nos resultados obtidos no monitoramento, para a verificação do que realmente foi cumprido em relação ao inicialmente planejado. Como dito anteriormente, são etapas distintas e complementares; nesse contexto, indissociáveis!

Por se tratar de uma prática recente nos órgãos governamentais, é um desafio para os agentes públicos estabelecer parâmetros e mecanismos para efetivar o processo de monitoramento e avaliação dos programas e políticas institucionais, o que não é diferente na área educacional.

Como e quando monitorar? Quando avaliar? Qual a diferença entre monitorar e avaliar? Quem são os responsáveis? Qual a periodicidade para monitorar? E para avaliar? Essas e tantas outras indagações surgem quando da necessidade de efetivar se dar consecução ao processo de monitoramento e avaliação. Partes dessas questões foram equacionadas nos planos decenais ao se definirem prazos, metas intermediárias, os responsáveis pelo monitoramento e avaliação, dentre outros. O esforço seguinte é criar condições para que o processo de implementação, monitoramento e avaliação dos planos efetivamente ocorra.

Nesse cenário, para monitorar e avaliar planos de educação com vistas à superação de desigualdades nos territórios e a efetividade do PNE, é basilar que os gestores públicos sejam os responsáveis por instalar e apoiar o processo, estimulando as pactuações e acordos necessários para a realização do trabalho a ser feito, de forma a agregar todas as instituições necessárias envolvendo diretamente a participação da sociedade organizada. Importante é destacar, nesse processo, o papel dos fóruns nacional, estaduais, distrital e municipais de educação.

Visando à implantação ou implementação de um processo de monitoramento e avaliação de planos de educação, cuja perspectiva seja a mobilização e participação social, com o alinhamento dos processos de gestão e das políticas educação, apresentamos a seguir algumas contribuições: (a) o monitoramento e a avaliação de um plano de educação deve ser compreendido 
como processo único em que não é possível o monitoramento sem que, periodicamente, ocorram avaliações. De igual forma, não convém avaliar sem que haja informações obtidas a partir do monitoramento contínuo do que foi proposto por meio de indicadores adequados; (b) a mobilização e a participação da sociedade no acompanhamento do processo de monitoramento e avaliação dos planos são condições indispensáveis para garantir transparência e acesso a todas as informações, bem como para contribuir para o efetivo cumprimento das metas e estratégias; (c) os gestores da política educacional (secretários de educação ou similares, diretores coordenadores) e os profissionais da educação são lideranças reconhecidas no âmbito do território e, consequentemente, são importantes articuladores de toda ação a ser desenvolvida; (d) as equipes responsáveis pelo processo precisam estabelecer cronograma de trabalho, assim como os respectivos responsáveis por cada uma das ações a serem empreendidas, com momentos para análise e replanejamento; (e) faz-se necessário, ainda, o estabelecimento de indicadores e instrumentos de gestão das informações a serem aferidas durante todo o trabalho realizado, com vistas à organização da série histórica e do banco de dados.

\section{CONSIDERAÇÕES FINAIS}

Certamente, a tarefa a ser desenvolvida acerca do monitoramento contínuo e das avaliações periódicas ao longo da vigência de um plano decenal é de uma grandeza e importância imensuráveis, principalmente quando relacionada a uma área tão complexa como a educacional. Romper com o paradigma da falta de acompanhamento que assola as políticas estruturantes será o início de mudanças significativas na gestão pública da educação.

Nesse contexto, partindo do pressuposto analítico de que os processos de proposição e materialização de planos de educação são complexos e que, portanto, não se efetivam de maneira linear, sinalizamos ao longo do texto, a importância de se garantirem condições objetivas e políticas direcionadas ao efetivo cumprimento das metas e estratégias. Nessa direção, é imprescindível que o planejamento, a proposição de políticas e a produção de indicadores se articulem como epicentro das políticas educacionais ao processo de monitoramento e avaliação do plano.

Logo, torna-se necessário que todos os entes federativos estejam imbuídos de seu papel para que, a partir da aprovação e sanção de seus respectivos planos de educação, cada território assuma um compromisso com o desenvolvimento de todos os cidadãos que ali residem, tendo como mola propulsora a implementação da política educacional. 
Obviamente, ao passo que cada estado, município e o Distrito Federal avançam no cumprimento das metas e estratégias propostas em seus planos, cumprindo assim as diretrizes determinadas em lei, o PNE, articulada a esse movimento de consolidação, a proposição de políticas e programas nacionais se consolidará e nosso País avançará nos indicadores de qualidade social da educação para todos.

No que se refere ao processo de monitoramento e avaliação, não existe fórmula pronta que possa ser replicada em todos os lugares, mas, sim, a necessidade de que todos os cidadãos - principalmente os gestores e profissionais da educação - articulados aos responsáveis legais por esse processo - coloquem em prática tudo que foi pensado, discutido e transformado em lei, que, em realidade, consta dos planos de educação, e de que os ajustes necessários sejam feitos no percurso. Trata-se de processo complexo que irá requerer mobilização permanente da sociedade civil e política e, especialmente, dos atores definidos nos planos como responsáveis pelo monitoramento e pela avaliação. Em outras palavras, a aprovação dos planos e sua materialização não se efetivam de maneira linear; são dois momentos articulados cuja convergência demandará ações efetivas em direção ao cumprimento das metas e estratégias e a garantia dos planos como epicentro às políticas educacionais brasileiras no âmbito nacional, estadual, municipal e local.

\section{REFERÊNCIAS}

BRASIL. Constituição da República Federativa do Brasil. Diário Oficial da União (DOU), Seção I, p. 1, 5 de outubro de 1988. Brasília: Senado Federal. 1988.

. LDB. Lei 9394/96. Lei de Diretrizes e Bases da Educação Nacional. Disponível em:< http://www.planalto.gov.br/ccivil_03/Leis/L9394.htm>. Acesso em: 26 jan. 2016.

Emenda Constitucional no 59 de 2009. Disponível em: < http:/ /www. planalto.gov.br/ccivil_03/constituicao/emendas/emc/emc59.htm>. Acesso em: 26 jan. 2016.

. Lei $\mathbf{n}^{\mathbf{0}}$ 13.005, de 25 de junho de 2014. Disponível em: http://www. planalto.gov.br/ccivil_03/_ato2011-2014/2014/lei/113005.htm>. Acesso em: 26 jan. 2016. 
O Sistema Nacional de Educação: diversos olhares 80 anos após o Manifesto. Ministério da Educação. Secretaria de Articulação com os Sistemas de Ensino - Brasília, DF: MEC/SASE, 2014.

. Instituto Nacional de Estudos e Pesquisas Educacionais Anísio Teixeira. Plano Nacional de Educação PNE 2014-2024: Linha de Base. - Brasília, DF: Inep, 2015.

. Secretaria de Articulação com os Sistemas de Ensino (SASE). Planejando a Próxima Década. Alinhando os Planos de Educação. Brasília: MEC, 2014.

MEC, 2014.

Conhecendo as 20 Metas do Plano Nacional de Educação. Brasilia:

O Plano Municipal de Educação: Caderno de Orientações. Brasília: MEC, 2014.

. Documento Final Conferência Nacional de Educação (CONAE)

2010. Disponível em:<http://conae.mec.gov.br/images/stories/pdf/pdf/ documetos/documento_final_sl.pdf>. Acesso em: 26 jan. 2016.

Documento Final Conferência Nacional de Educação (CONAE) 2014. Disponível em:<http:/ / conae2014.mec.gov.br/noticias/500-fne-apresentadocumento-final-da-conae-2014>. Acesso em: 26 jan. 2016.

BRITO, Jorge Nei e SABARIZ, Antônio Luiz Ribeiro. Elaboração e gestão de projetos educacionais — São João Del-Rei, MG : UFSJ, 2011.

DOURADO, Luiz Fernandes. Sistema Nacional de Educação, Federalismo e os obstáculos ao direito à educação básica. Educ. Soc. [online]. 2013, vol.34, n.124, pp.761-785. ISSN 0101-7330. http://dx.doi.org/10.1590/S010173302013000300007.

Avaliação do Plano Nacional de Educação 2001-2009: questões estruturais e conjunturais de uma política. Educ. Soc. [online]. 2010, vol.31, n.112, pp.677-705. ISSN 0101-7330. http://dx.doi.org/10.1590/S010173302010000300003 . 
LUIZ FERNANDES DOURADO é doutor em Educação e professor titular e Emérito da Faculdade de Educação da Universidade Federal de Goiás (UFG), Membro do Conselho Nacional de Educação (2012/2016) e dos Conselhos Superior e CTC-EB da Capes. E-mail: luizdourado1@gmail.com

GERALDO GROSSI JUNIOR é professor da Rede Estadual de Ensino do Mato Grosso; Mestre em Educação, Diretor de Cooperação e Planos de Educação do Ministério da Educação (MEC). E-mail: jrgrossi@terra.com.br

ROBERVAL ANGELO FURTADO é Professor e Especialista em Educação da Rede Municipal de Ensino de Campo Grande (MS), Coordenador-Geral de Implantação dos Planos Estaduais e Municipais de Educação do Ministério da Educação (MEC). E-mail: robervalfurtado@gmail.com 